\title{
Cambios percibidos en la vida cotidiana por adultos que viven con VIH
}

Changes perceived in daily life by adults living with HIV

\author{
LemyBran-Piedrahita / lbpiedrahita@ucn.edu.co \\ http://orcid.org/0000-0001-5114-9081 \\ Fundación Universitaria Católica del Norte, Colombia \\ Lucía Palacios-Moya / ciessalud3@escolme.edu.co \\ http://orcid.org/0000-0003-3891-0862 \\ Institución Universitaria Escolme, Colombia
}

Viviana Bermúdez-Román / vivibermudez0412@gmail.com

http://orcid.org/0000-0001-6963-9054

Isabel Cristina Posada-Zapata / isabel.posada@udea.edu.co

http://orcid.org/0000-0003-4953-6490

Universidad de Antioquia, Colombia

\begin{abstract}
The aim of this work is to understand the perception of adults living with HIV in the city of Medellin, Colombia, regarding the social and economic changes produced in their daily life by the disease. A qualitative study was developed. The information was collected with semi-structured interviews and for its analysis elements of the Grounded Theory were taken into account. Changes in daily life are reflected in the reconfiguration of the self-image, the forms of family relationships and the financial dependence as a result of the complications derived from the virus and the stigma of the disease. It is pertinent to develop studies on this subject with a gender approach, given the hermetic attitude of women living with the disease to talk about it.
\end{abstract}

Key words: quality of life, discrimination, perception, interpersonal relations, HIV/AIDS.

Resumen: El objetivo del trabajo es comprender la percepción de adultos que viven con VIH en la ciudad de Medellín, respecto a los cambios sociales y económicos en su vida cotidiana, propiciados por la enfermedad. Se realizó un estudio cualitativo; la información se recolectó de entrevistas semiestructuradas, y para su análisis se tomaron en cuenta elementos de la Teoría Fundamentada. Se observó que los cambios en la cotidianidad se reflejan en reconfiguraciones de la autoimagen, formas de relacionamiento familiar y en la dependencia financiera resultante de las complicaciones derivadas del virus y por el estigma de la enfermedad, que lleva a las personas seropositivas a ser rechazadas en el mercado laboral. Se concluye que es pertinente realizar estudios en esta temática con un enfoque de género, dado el hermetismo de las mujeres que viven con la enfermedad para hablar al respecto.

Palabras clave: calidad de vida, discriminación, percepción, relaciones interpersonales, VIH/Sida. 


\section{Introducción}

El Virus de Inmunodeficiencia Humana (VIH) infecta las células del sistema inmunitario, lo cual altera su funcionamiento para garantizar la protección del organismo ante agentes invasores. En contraparte, el Síndrome de Inmunodeficiencia Adquirida (Sida) se considera la etapa progresiva del virus, definido por la presencia de alguna de las 20 infecciones oportunistas o tipos de carcinomas asociados al contagio con VIH (Díaz et al., 2014).

Desde el descubrimiento de los primeros casos, donde los infectados resultaron ser varones homosexuales, el virus ha estado rodeado de una serie de significados sociales y mitos, propiciando un marcado estigma en torno a la enfermedad. A esto se suma el comportamiento variado de la epidemia en el mundo, donde se evidencian en los últimos años reducciones significativas en el número de contagiados en regiones como África Subsahariana, así como el incremento en otras zonas como Asia Central y Europa Oriental (Teva et al., 2012; Bermúdez et al., 2015).

De este modo, la epidemia se ha expandido considerablemente en los últimos años, dejando de lado las barreras iniciales que hacían referencia a grupos de riesgo como hombres que tienen sexo con hombres, mujeres trabajadoras sexuales o usuarios de drogas inyectables; ampliando su espectro a diferentes conglomerados sociales, lo cual no sólo ha incrementado el número de casos, sino que también ha hecho más vulnerables las comunidades ante el virus (García et al., 2014).

En este panorama, de acuerdo con el Programa Conjunto de las Naciones Unidas sobre el VIH/Sida (ONUSIDA, 2017), desde los primeros reportes generados por la epidemia, en el mundo más de 78 millones de personas han contraído la enfermedad, señalando además que para el año 2016 cerca de 36,7 millones vivían con el virus, con la peculiaridad de que el mayor número de estos casos se dieron en países de bajos y medianos ingresos; lo cual se pone en evidencia con naciones del sur de Âfrica como Angola, Botsuana, Lesoto, Malawi, Mozambique, Namibia, Sudáfrica, Suazilandia, Zambia y Zimbabue, que continúan siendo no sólo la región más afectada del continente, sino también el epicentro generalizado de la epidemia (Vermund, 2014; Angulo, 2015; ONUSIDA, 2017).

En Colombia, la infección es considerada como un problema de salud pública, debido a los altos costos que genera para el sistema sanitario en los niveles de promoción de la salud, diagnóstico, tratamiento y rehabilitación de la enfermedad, y por el incremento paulatino de casos registrados en el país, donde en el periodo desde 1985 hasta 2011 se habían reportado un total 
de 75.620 infecciones, y para el año 2014 había 9.700 nuevos casos reportados en el sistema de vigilancia epidemiológica colombiano (Cardona e Higuita, 2014; Gaviria et al., 2015; Angulo, 2015).

En este escenario, las investigaciones sobre la enfermedad deben enfocarse no sólo al reconocimiento de la magnitud epidemiológica del virus, sino también en otros aspectos trascendentales, como las representaciones sociales construidas alrededor del VIH, donde éste adquiere una connotación de agente contagioso, mortal y asociado a unos grupos minoritarios, lo cual, como se ha mencionado previamente, ha encontrado fundamento en la historia social de la infección, vinculada a personas homosexuales y farmacodependientes, llamadas entonces "grupos inmorales" (Cantú et al., 2012).

De esta forma, el desconocimiento respecto al virus y los marcados estigmas construidos a lo largo de la historia en torno a la enfermedad, se configuran con el impacto negativo que tiene el diagnóstico como seropositivo; esto propicia una serie de cambios psicológicos y sociales en quienes viven con VIH, que les llevan a ocultar su condición por temor a ser rechazados por familiares y grupos sociales, además del temor implícito de poder morir a causa de la infección. Asimismo, el entorno de estigmatización que ha acompañado la historia social de la infección lleva además hacia otros problemas sociales, como la pérdida de empleo, vivienda y posición social (Tamayo et al., 2015; Chong et al., 2012).

En su estudio, Sowell y Phillips (2010) refieren cómo los antecedentes mismos asociados a la infección han ocasionado que la enfermedad esté vinculada con determinados grupos de individuos o se le considere un castigo divino, lo cual no sólo ha provocado que los esfuerzos emprendidos para prevenir la epidemia resulten limitados, sino también ha hecho más recalcitrante el rechazo generalizado socialmente por los significados sociales construidos alrededor del virus.

Del mismo modo, como consecuencia del marcado estigma y las afecciones que derivan de la enfermedad, Vargas et al. (2009) exponen en su trabajo la serie de cambios internos que experimentan las personas seropositivas, lo que involucra una diversidad de emociones que conducen no sólo a la presencia constante de cuadros depresivos, sino también al menoscabo de la calidad de vida de quien vive con la infección. Por otro lado, Almanza y Flores (2012) señalan que la enfermedad trae consigo una serie de modificaciones en el estilo de vida, debido al carácter crónico que representa el VIH.

A estos cambios endógenos experimentados por cada sujeto infectado, se suman las transformaciones en el relacionamiento con sus pares más cercanos, como es el caso de los amigos, la familia o compañeros de trabajo. Al 
respecto, Almanza y Flores (2012) refieren el impacto que tienen los constructos sociales de la enfermedad, como la asociación del virus con la muerte, así como el temor al contagio ante el contacto más simple, lo cual conduce al rechazo del círculo social más cercano al individuo seropositivo.

Lo anterior es consecuente con otros estudios como el de Ahumada et al. (2011), donde se reconoce el rol protagónico del apoyo social para este grupo de personas, reflejando cómo el ambiente social para individuos seropositivos se constituye en un complejo sistema de matices culturales, psicológicos e interpersonales, que afectan el proceso de salud- enfermedad en quienes viven con la infección y también factores conductuales. Asimismo, los planteamientos de Orcasita et al. (2010) proyectan dicho apoyo como un eje en el desarrollo individual y familiar, respondiendo a las necesidades que emergen a lo largo del proceso evolutivo de cada sujeto.

De ahí que el interés por estudiar todas estas problemáticas en torno al VIH y al Sida no sea un tema reciente en el campo de la salud colectiva y las ciencias sociales (Passerino, 2013); treinta años después de la aparición de los primeros casos de la enfermedad continúa siendo una temática interesante desde una perspectiva biomédica y las consecuencias psicológicas y sociales (Nhamba et al., 2014).

Adicionalmente, Tavera (2010) revela en su estudio cómo durante los últimos diez años se han efectuado numerosas investigaciones que trascienden la dimensión biomédica, abordando aspectos psicológicos, sociales y económicos de esta enfermedad, con la finalidad de evaluar el impacto que propicia el virus en la calidad de vida de quienes contraen la infección.

Por otra parte, aunado a los cambios sociales que han surgido con el virus, deben considerarse las transformaciones económicas derivadas del diagnóstico con VIH, más cuando la infección se ha desarrollado en el marco de un mercado globalizado, donde las brechas entre ricos y pobres han sido tan marcadas; esto ha generado desigualdad y exclusión social como consecuencia de la concentración de la riqueza (Chong et al., 2012).

Arrivillaga et al. (2009) ponen de manifiesto cómo en el contexto latinoamericano y la región Caribe, la inequidad social y económica se consolidan como propulsores de un incremento desmesurado en las tasas de infección por VIH, así como en el surgimiento del Sida como etapa progresiva del virus.

Desde la perspectiva económica, Salcedo et al. (2013) destacan el impacto que propicia la infección para el desarrollo económico de las naciones, no sólo por los altos costos que genera para los sistemas sanitarios, sino también por atacar la fuerza de trabajo - población en edad de laborar-, ampliar 
el espectro de la desigualdad y menoscabar los derechos laborales de las personas, por la discriminación y estigma generalmente asociados al VIH.

En esta misma dirección, Meléndez (2014: 9) expone cómo los cambios acaecidos en la vida de quien se infecta con VIH no sólo involucran la dimensión biomédica, como ya se ha hecho referencia, sino que también el diagnóstico trae consigo una serie de secuelas en la dimensión económica: generación de pobreza, pérdida de estatus social y el desempleo, lo cual golpea enormemente al individuo seropositivo y a sus familias.

Estas transformaciones se sustentan, además, de acuerdo con Lopera et al. (2011), en las barreras de acceso existentes en el sistema de salud colombiano, donde las personas y sus familias deben asumir costos adicionales para la adquisición de medicamentos, consultas médicas particulares o suplementos alimenticios, sin contar con el impacto que generan las incapacidades de quien vive con el virus -lucro cesante-.

A lo anterior, se suma el hecho que, de acuerdo con López et al. (2009), la mayoría de los estudios económicos asociados con este grupo poblacional, apuntan a los costos que deben asumir las personas infectadas ante las fisuras que se presentan en los sistemas sanitarios, lo cual deja ver que más allá del estigma, las relaciones de dependencia financiera están vinculadas con las recaídas que trae consigo el debilitamiento del sistema inmunológico y las endebles políticas de seguridad social.

En este sentido, son diversos los estudios que han aclarado respecto a cómo los impactos económicos asociables a la enfermedad tienden a ser percibidos en mayor grado por sectores en desventaja social y Estados con menor desarrollo a nivel global. De allí que la inseguridad económica sea más recalcitrante, cuando se configura junto al marcado estigma y discriminación social de los cuales son víctimas las personas seropositivas. Por ello las dimensiones sociales y económicas, a la luz de otras investigaciones, impactan la calidad de vida de las personas que viven con VIH y sus familias; situación que en el contexto colombiano se torna preocupante cuando se considera la desventaja que tienen, sólo por citar un ejemplo, las mujeres infectadas respecto a la población masculina (Domínguez y Domínguez, 2005; Katz et al., 2013; Cardona et al., 2010).

Por lo tanto, se planteó una investigación cuyo objetivo fue comprender la percepción de adultos que viven con VIH en la ciudad de Medellín, en cuanto a los cambios sociales y económicos en su vida cotidiana, propiciados por el virus para el periodo 2012-2013, con la finalidad de proveer información de referencia para un abordaje integral de la enfermedad, desde aportes provenientes de la articulación entre la salud pública y las ciencias sociales. 


\section{Metodología}

Se realizó una investigación cualitativa, considerando que una de las principales ventajas de este método radica en la posibilidad que otorga al investigador para comprender de manera holística el fenómeno que da origen al estudio; reconociendo además que este tipo de investigaciones permiten llevar a cabo una valoración subjetiva en torno a las tradiciones, roles y valores compartidos, así como los comportamientos individuales y colectivos de los seres humanos (Valerio y Valenzuela, 2011; Ghiso y Ospina, 2010).

En cuanto a la ruta orientadora del estudio, se optó por el enfoque hermenéutico, tomando como referente teórico los postulados de Gadamer (1998), quien reconoce la hermenéutica como el arte o la teoría de la interpretación, que para el caso de este estudio se pretendió comprender los cambios sociales y económicos percibidos por la población de referencia, siendo ello posible a través del diálogo.

Como población de referencia se consideraron personas adultas -en el contexto legal colombiano, mayores de 18 años de edad-, diagnosticadas con el VIH, quienes debían cumplir como criterios de inclusión: la mayoría de edad, residir en la ciudad de Medellín y utilizar servicios de salud en la localidad. Como criterio de exclusión del estudio se tomó en cuenta el hecho de padecer un trastorno mental severo que les impidiera participar con pleno conocimiento de los alcances de la investigación -para identificar dichos trastornos, se parte de los registros de las fundaciones donde fueron contactados los participantes-.

En este orden de ideas, la investigación contó con un total de 13 informantes clave, de los cuáles sólo tres eran mujeres, debido a que el acceso a esta población fue mucho más complejo, por el hermetismo que asumen ellas frente a su diagnóstico, ante el marcado estigma erigido alrededor del virus. Los participantes fueron contactados a través de los grupos de apoyo en la ciudad de Medellín, con las fundaciones Red de Apoyo Social de Antioquia (RASA) y Eudes, las cuales no sólo brindaron los espacios para recolectar la información, sino también abrieron sus puertas para permitir una mayor proximidad con la población objeto de estudio, hecho que sin lugar a dudas enriqueció el trabajo de campo.

Como consideraciones éticas garantes de la participación en el estudio, se tomaron en cuenta los principios establecidos por la Declaración Universal de los Derechos Humanos, como compromiso ético de los diversos Estados y de sus instituciones. Asimismo, el equipo investigador consideró la aplicabilidad de la Declaración de Helsinki (Asociación Médica Mundial, 
2013), que si bien hace referencia a estudios clínicos, se ha constituido en los últimos años en la piedra angular de la incorporación de elementos axiológicos en la investigación, lo cual ha llevado al sometimiento de proyectos de diversa índole a un comité ético que asegure la integridad de los participantes (Pfeiffer, 2009).

Por lo tanto, al cumplir dichas directrices internacionales y la normatividad nacional estipulada a través de la Resolución 8430 de 1993 del Ministerio de Salud y Protección Social -que establece las normas técnicas, científicas y administrativas para las investigaciones que involucren seres humanos (Bejarano et al., 2011)-, el estudio se sometió a evaluación del Comité de Ética de la Investigación de la Facultad Nacional de Salud Pública de la Universidad de Antioquia, quienes lo catalogaron como de "riesgo mínimo", dado que no se pretendían modificar estructuras físicas o psicológicas de los informantes.

Adicionalmente, para recolectar la información, se utilizaron entrevistas semiestructuradas a profundidad, cuyos instrumentos fueron diseñados con base en los objetivos específicos de la investigación, garantizando la consecución del objetivo formulado. Para ello se abordaron preguntas por temáticas relacionadas con vivencias y cambios de la enfermedad, conocimiento sobre ésta, conocimiento y uso de los servicios de salud desde la fase de promoción hasta diagnóstico, tratamiento y rehabilitación.

Una vez que se realizaron las entrevistas, como técnica para analizar la información encontrada, se tomaron en consideración elementos medulares de la Teoría Fundamentada, como la codificación y la categorización, método propuesto inicialmente por Barney Glaser y Anselm Strauss, y luego replanteado por este último autor en compañía de Juliet Corbin (Trinidad et al., 2006: 20).

\section{Resultados}

A lo largo de la historia de los seres humanos, la enfermedad ha estado rodeada de una pluralidad de significados que genera en quienes viven con ella manifestaciones físicas, sociales, económicas o culturales. En este sentido, no puede desconocerse que si bien la connotación de la persona enferma propicia toda una serie de afecciones en las dimensiones ya mencionadas, a lo largo de los años algunas condiciones mórbidas han tenido un significado más marcado para quien las presenta (Morales et al., 2012; Camargo, 2016), como ha sido el caso de la lepra, el cáncer y el VIH.

Estos significados han estado estructurados por las representaciones sociales creadas en torno a dichas enfermedades, donde se asumen como un 
castigo divino por acciones reprochables moralmente, o como en el caso de la población seropositiva, una infección que se adquiere por grupos desviados de las conductas "normalmente aceptadas" (Jacques et al., 2015; Valdez et al., 2015; Sánchez et al., 2016).

En este orden de ideas, este estudio logró comprender a través de los testimonios de adultos que viven con VIH en la ciudad de Medellín los cambios percibidos en las dimensiones sociales y económicas, cambios que pueden ser diversos según las relaciones construidas, autoimagen, búsqueda de redes de apoyo, entre otras

Respecto a los cambios sociales de quienes adquieren la enfermedad, a lo largo de este estudio ciertos participantes durante el desarrollo de las entrevistas hicieron referencia al impacto que genera el estigma y discriminación erigidos alrededor del virus, en el relacionamiento no sólo con sus pares, sino también en la percepción que tienen de sí mismos, evidenciando que una de las transformaciones más relevantes gira en torno a la autoimagen que tienen las personas al ser diagnosticadas con el VIH, tal como lo expresaron algunos informantes clave:

Las cosas cambian, la gente ya no lo ve igual, ni los amigos del alma ni los nada, ya es distinto.

No sé qué sentiría hoy, porque sería muy distinto y muy difícil decir qué sentiría hoy, en ese momento me dio muy duro, pensé que me iba a morir porque no había cura, eso era una sentencia de muerte, no había ni la red de apoyo, ni los medicamentos, ni el conocimiento, ni había nada, ni siquiera la EPS. ${ }^{1}$

Como puede observarse en los fragmentos anteriores, la reconfiguración de la imagen que tiene el sujeto de sí mismo a raíz del diagnóstico se ve influida por estigmas creados alrededor del virus, como la relación de éste con la muerte, y, a su vez, resalta la posibilidad de asumir el diagnóstico de una mejor manera cuando existen redes de apoyo sociales; situación que, por consiguiente, permite generar un cambio en lo que es su proyecto de vida, así como lo expresa uno de los entrevistados:

Cuando a mí me diagnosticaron, yo estaba haciendo una especialización en la Universidad del Rosario, yo creo que eso es lo que más ha dolido, porque uno a la Universidad del Rosario no entra por méritos propios, uno tiene que entrar por palanca, además por mérito propio hay que ponerle palanca y yo no fui capaz, porque me diagnosticaron cuando estaba terminando el primer semestre, entonces ya no, pues el mundo se me... pues es que eso es muy difícil describirlo.

1 Cuando el informante se refiere a la sigla "EPS" alude a las Empresas Promotoras de Salud, figura que en el sistema de salud colombiano cumplen las compañías de aseguramiento frente a las adversidades que puedan acontecer a causa de enfermedad o accidente común. 
Lemy Bran-Piedrahita, Lucía Palacios-Moya, Viviana Bermúdez-Román e Isabel Cristina PosadaZapata. Cambios percibidos en la vida cotidiana por adultos que viven con VIH

El momento que fui diagnosticada sentí que el mundo se me acabó en ese momento, el mundo se me vino encima, me dio una depresión muy fuerte por el miedo al rechazo de la sociedad, el temor de infectar a mi familia, aunque uno sabe que el VIH no se contagia fácilmente, pero aún así existe el temor, no sé, usted sabe, esos mitos que a veces le pueden más a uno que cualquier otra cosa. (E11, p1)

Lo expresado anteriormente evidencia los cambios sociales experimentados en el relacionamiento del sujeto consigo mismo; sin embargo, ésta no es la única dimensión que resulta alterada con el diagnóstico. A lo largo de este estudio, los informantes hicieron referencia a cómo la forma de interactuar con sus pares -familia, amigos o compañeros de trabajo- también resultaba estropeada con su condición como seropositivos, aunque también se muestra un deseo de protección ante la familia:

Esas vainas dizque la familia lo ama a uno, que uno es lo más importante y esas cosas, eso es mentira, porque haga usted el ensayo, enférmese, yo lo invito a usted a que empiece y diga me duele esto, me duele aquello, me duele el pelo, hágame el favor de lo de más allá, y segurito que empieza a molestar, hasta ahí les llega el amor, usted es importante en su familia y lo quieren mientras esté aliviado, y peor aun cuando uno tiene cáncer, diabetes o VIH como es mi caso y ya a uno no lo quieren más, la familia te ve raro, como con fastidio o miedo a veces, la verdad eso es de lo que me ha dolido a mí más.

Entonces, debe rescatarse que si bien los participantes hicieron alusión a las transformaciones sociales suscitadas en sus vidas a raíz del diagnóstico, donde algunos identificaron efectos negativos, otros informantes refirieron cambios positivos por parte de sus amigos y familiares, lo cual, contrario al testimonio anterior, pone en evidencia la dualidad que puede presentarse en este sentido, dependiendo de la solidez de los vínculos afectivos y la relevancia que le confieren las personas a los estigmas existentes en torno al virus, tal como lo manifiestan algunos entrevistados:

Yo a diferencia de otros he tenido muy buen apoyo familiar, y parto de ahí, cuando se tiene ese apoyo familiar y cuando estás consolidado en el grupo familiar, en tu casa, hablo de la casa, del entorno de donde estás, donde estás con mamá, papá, hermanos y hay ese respeto y hay ese apoyo, desde ahí uno parte. El diagnóstico no te afecta tanto, cuando tenés el apoyo, cuando estás bien ahí.

Pues no sé, gracias no sé si es a la vida o a Dios, he contado con muy buenos amigos, con una pareja que me ayudó mucho, con mi familia principalmente, pues de mi familia sólo sabe mi mamá y ya, pero muchos amigos míos saben, pero lo bonito es que con esta situación uno en verdad se da cuenta quiénes te van a acompañar en los momentos difíciles y cuando vos los necesites.

Asimismo, es pertinente destacar que aunque si bien se comparten cambios similares por tener la condición de seropositivo, éstos varían y tienen 
una mayor carga según el grupo poblacional al que se pertenezca. De hecho, se ha demostrado que existe una equivalencia VIH-homosexual, VIH- trabajadora sexual, situación que influye en que la condición de ser mujer sea por cuestiones morales más difícil de aceptar:

Después de mi diagnóstico mi marido me dejó, él no supo entender que yo había quedado infectada no por $f u f a^{2}$ o esas cosas que él pensaba, sino por mi trabajo, por una de esas malas jugadas del destino, él simplemente en medio de su ignorancia no me supo entender y se fue, que porque yo era una fufa que ya le daba miedo hasta dormir conmigo, imagínese, eso fue algo bien duro, aunque por fortuna ahí estuvo mi madre acompañándome y dándome apoyo; sin embargo, el marido es el marido, por algo uno se casa ¿no? (E11, p1)

En este sentido, es interesante destacar cómo si bien los estigmas y discriminación asociada al VIH han repercutido en la vida de quienes tienen la condición de seropositivos, llevándolos a reconfigurar la visión que tienen de sí mismos, así como el relacionamiento con sus pares, también se abre la posibilidad a otras posturas, donde lejos de la censura y de condenar al ostracismo a quien vive con la infección, se fortalece el vínculo afectivo entre el sujeto, su familia y red de amigos, lo cual incide positivamente en su cohesión social, que es en últimas uno de los aspectos más vulnerados en esta población.

Por otro lado, respecto a los cambios económicos también se presentan hallazgos significativos a la luz de la percepción de los participantes, quienes manifestaron cómo a raíz del contagio con el virus se van evidenciando paulatinamente modificaciones en temas claves como la independencia financiera y la inserción o mantenimiento en el mercado laboral.

Cuando los entrevistados relataban sus experiencias en torno a la independencia económica, se establece cómo las vivencias con VIH y la progresividad que puede llegar a tener el virus en el organismo -dependiendo de la adherencia o no al tratamiento-, así como el estado en que se haya efectuado el diagnóstico - es decir, la oportunidad en el diagnóstico-, llevan en muchas ocasiones a que abandonen su empleo por las constantes recaídas e infecciones que pueden afectar al organismo como consecuencia del debilitamiento inmunológico.

Así, las personas van perdiendo dicha independencia o autonomía para solventar sus gastos por sí mismos; esto conduce a una dependencia económica respecto a familiares, pareja o demás allegados. Tal como lo aseveran algunos informantes:

2 Cuando la participante hace referencia a la expresión fufa, alude a la forma como coloquialmente en algunas regiones de Colombia se le llama a las mujeres dedicadas a la prostitución. 
Lemy Bran-Piedrahita, Lucía Palacios-Moya, Viviana Bermúdez-Román e Isabel Cristina PosadaZapata. Cambios percibidos en la vida cotidiana por adultos que viven con $V I H$

La verdad como yo ni alcancé a tener una pensión, hoy por hoy dependo de mis papás, ellos afortunadamente me ayudan, aunque no deja de ser pesado, más cuando yo estaba enseñado a coger mi plata ${ }^{3}$ y todo eso, pero qué le hace uno ahí, en este país si se le complica conseguir trabajo a gente aliviada, imagínese uno ya enfermo.

No deja de ser maluco para uno tener que depender hasta de cosas mínimas como lo del aseo de uno de la familia, mis hermanas me quieren y pues si vienen me visitan y me dan plata, pero yo no desconozco que con mi enfermedad me les volví en una carga.

Sin embargo, ha de aclararse que dicha dependencia no obedece exclusivamente a causas de índole físico por las dificultades de salud que pudiesen experimentar las personas, pues por las experiencias relatadas por los participantes del estudio, el mismo constructo social que se ha dado en torno al VIH se edifica también como un agente determinante, en relación con los cambios económicos experimentados por quienes viven con el virus. Constantemente los entrevistados hicieron referencia a cómo el estigma y discriminación asociada a la condición como seropositivos constituyó un detonante clave en la pérdida de sus empleos o en el acceso al mercado laboral, tal como se valida en estos testimonios:

Qué empresa lo va a estar contratando si uno necesita prescripción regular cada mes, cada mes te están mandando donde el nutricionista, donde el neumólogo, donde el neurólogo, donde no sé qué, donde sí se cuándo, una vuelta, la otra, que vaya reclame medicamentos, que vaya para el comité , qué empresa va a permitirle eso a un empleado, no es garantía para ellos, si te contratan y luego saben que tienes Sida miran cómo sacarte, esa es la realidad.

Estamos en una sociedad que aún piensa que con tan sólo tocar a una persona que vive con VIH se infecta, he conocido casos de personas que han perdido su empleo por vivir con la enfermedad, hay mucha discriminación, ¿si existe discriminación racial no va existir discriminación con las personas que vivimos con VIH?

En el último empleo me pasó, eso fue muy contradictorio porque en mi trabajo se dieron cuenta y en la temporal ${ }^{5}$ también, en la temporal en el primer momento me

3 En el contexto colombiano, la expresión plata suele emplearse coloquialmente para referirse al dinero.

4 En el contexto colombiano, cuando el entrevistado hace referencia a la expresión "comité", éste alude a una de las estancias administrativas que operó hasta hace algún tiempo en Colombia por parte de las entidades aseguradoras, denominada "Comité Técnico Científico", a través del cual se gestionaba el acceso de los pacientes del sistema de salud a medicamentos, procedimientos y demás considerados de alto costo (como se considera al VIH).

5 La expresión "temporal" que utiliza el informante hace referencia a la denominación que han recibido en el país las empresas que laboran bajo la modalidad de tercerización; es decir, son compañías que se dedican a reclutar, vincular y gestionar todo lo relacionado con pago 
rechazó, pero en la empresa como tal nunca me rechazó, nunca, siempre me apoyaron, siempre estuvieron ahí, siempre me preguntaban cómo iba mi estado de salud, si me estaba tomando los medicamentos, mientras que en la temporal sí empezó a colocar una serie de trabas, digámoslo así.

Por tanto, a raíz de los argumentos expuestos por los diferentes informantes del estudio, puede evidenciarse cómo el diagnóstico con el VIH, más allá de propiciar una serie de cambios físicos en quienes viven con la infección -que ya han sido explorados con detenimiento en la literatura existente-, genera también una serie de modificaciones en el orden social que llevan a reconfigurar la percepción que tiene el individuo sobre sí mismo, así como su relacionamiento con el entorno, además de una serie de transformaciones económicas que abarcan limitantes para el acceso al mercado laboral y, por tanto, conducen, junto con el detrimento progresivo que genera la enfermedad en el organismo, a crear una dependencia financiera de los individuos seropositivos hacia los familiares y pares más próximos. Todo esto, como ya se ha dicho, alimentado por los significados socialmente aceptados que se han dado alrededor del virus, propiciando un estigma y temor recalcitrante, capaz incluso, a nuestro criterio, de generar mayores impactos que las manifestaciones biológicas asociadas a la enfermedad.

\section{Limitaciones}

Una de las principales limitantes que se presentaron durante la realización de este estudio consistió en lograr la participación de informantes femeninas, dado que éstas por los significados sociales existentes en torno a la enfermedad y el estigma persistente, prefieren ocultar su diagnóstico, lo cual las lleva a asumir posturas más herméticas que la población masculina cuando se trata de participar en este tipo de investigaciones.

\section{Conclusiones}

El diagnóstico con el VIH representa una serie de cambios en la cotidianidad de quien resulta infectado, y abarca dimensiones sociales y económicas en la vida del individuo. Estas reconfiguraciones experimentadas por las personas se ven influidas no sólo por las complicaciones biomédicas que se derivan de la enfermedad, sino también por la carga social que ha acompañado históri-

de salarios y prestaciones sociales a las empresas, de tal manera que éstas puedan ser más eficientes, enfocándose en sus actividades medulares. 
camente la infección, lo cual ha llevado a entretejer un marcado estigma que conduce a excluir a quien adquiera la condición de seropositivo.

En este sentido, los cambios en la cotidianidad, desde una perspectiva social, llevan a que se modifique la percepción que tiene el individuo de sí mismo, pues el asumir el diagnóstico de una enfermedad que históricamente se ha asociado a grupos "desviados" socialmente y con imaginarios que le vinculan con el pecado o la muerte, ocasionan que las personas se vean a sí mismos con matices diferenciales - por lo general, negativos-. De igual manera, estas mismas representaciones sociales que replantean la autoimagen de cada sujeto generan que el relacionamiento con sus pares -incluida la familia, círculo de amigos y entorno laboral- se vea alterado, pues en la mayoría de los casos los mitos e imaginarios que se han erigido respecto a la infección llevan a que éstos sean rechazados, con lo cual se vulnera su cohesión social con los colectivos a los que pertenecen.

Sin embargo, aunque la enfermedad tiene una carga social alimentada por los estigmas y representaciones sociales construidas alrededor de la misma $-\mathrm{y}$ tanto los resultados de esta investigación como otras afines develan el rechazo del que son víctimas las personas seropositivas-, debe reconocerse también la cara opuesta, pues existen otros casos donde la infección de un individuo con el virus ocasionan que el vínculo afectivo con su familia se afiance, lo cual favorece sus estrategias para afrontar la enfermedad. Esto evidencia la ambivalencia que pueden tener las percepciones de la población objeto de estudio respecto a los cambios sociales derivados del diagnóstico en su vida cotidiana.

Ahora, desde una perspectiva económica, el diagnóstico con VIH también propicia una serie de cambios desde la cotidianidad de los individuos. Éstos se encuentran determinados con aspectos sociales como el estigma y la discriminación de los cuales son víctimas los individuos seropositivos, que conducen a percibir barreras para acceder o permanecer en el mercado laboral; sin embargo, a esto se suman también los efectos que generan las manifestaciones biomédicas y psicológicas asociadas al virus.

De este modo, el presente estudio devela un panorama interesante de un problema de salud pública y la forma en que se imbrica con campos de interés de las ciencias sociales. Esto pone de manifiesto tres realidades: la primera refleja la pertinencia que tienen a la fecha los estudios con población seropositiva, no sólo por la magnitud del problema respecto al número de casos reportados, sino también porque sus efectos trascienden la dimensión biomédica, implicando aspectos psicológicos, sociales, económicos y culturales. 
La segunda deja en evidencia la transversalidad de las ciencias sociales con los diferentes campos del saber, por las herramientas metodológicas y de análisis que puede proveer, y por la complejidad de las realidades humanas, que aunque pueden abordarse desde ámbitos como la salud pública, precisan comprender el contexto donde suceden los problemas, lo cual desde las ciencias sociales es posible abordar holísticamente.

Y la tercera pone de manifiesto la importancia de realizar otras investigaciones en el campo con enfoque de género, pues, como se señaló previamente, una de las limitaciones de este estudio consistió en poder garantizar la participación de la población femenina, debido a sus posturas herméticas para hablar abiertamente del diagnóstico, los significados y experiencias vividas a raíz de contraer la infección, lo cual obedece al estigma que se ha creado alrededor del VIH. Por lo tanto, abordar estas experiencias y percepciones frente a los cambios sociales y económicos en sus vidas cotidianas a raíz del diagnóstico, es un aspecto de sumo interés, más en contextos como el latinoamericano, donde la reivindicación de la mujer es aún una temática con saldos pendientes en una sociedad caracterizada por el machismo y la exclusión de ellas.

\section{Referencias}

Ahumada, Marcelo et al. (2011), "Estudio preliminar de las relaciones entre las estrategias de afrontamiento y el apoyo social con la adherencia al tratamiento de personas que viven con VIH/SIDA", en Subjetividad y Procesos Cognitivos, vol. 15, núm. 1, Argentina: Universidad de Ciencias Empresariales y Sociales.

Almanza, Ariagor y Flores, Fátima (2012), "Resistencia a la discriminación: narrativas familiares acerca de la infección por VIH. Un estudio exploratorio”, en Psicología y Salud, vol. 22, núm. 2, México: Instituto de Investigaciones Psicológicas de la Universidad Veracruzana.

Angulo, Yeferson (2015), "En la infección por VIH, ¿es mejor prevenir que curar?”, en Médicas UIS, vol. 18, núm. 2, Colombia: Universidad Industrial de Santander.

Arrivillaga, Marcela et al. (2009), "Políticas públicas, sistema de salud y mujeres con VIH/ Sida en Colombia: Un análisis crítico”, en Gerencia y Politicas en Salud, vol. 8, núm. 16, Colombia: Pontificia Universidad Javeriana.

Asociación Médica Mundial (2013), Declaración de Helsinki. Disponible en: https://www. wma.net/es/policies-post/declaracion-de-helsinki-de-la-amm-principios-eticos-paralas-investigaciones-medicas-en-seres-humanos/ [30 de octubre de 2017].

Bejarano, Mónica et al. (2011), "Frecuencia de abdomen agudo quirúrgico en pacientes que consultan al servicio de urgencias”, en Revista Colombiana de Cirugía, vol. 26, núm. 1, Colombia: Asociación Colombiana de Cirugía.

Bermúdez, Viviana et al. (2015), "Influencia del estigma en torno al VIH en el acceso a los servicios de salud”, en Salud Pública de México, vol. 57, núm. 3, México: Instituto Nacional de Salud Pública. 
Lemy Bran-Piedrahita, Lucía Palacios-Moya, Viviana Bermúdez-Román e Isabel Cristina PosadaZapata. Cambios percibidos en la vida cotidiana por adultos que viven con $V I H$

Camargo, A. (2016), "Cuidando demonios, vampiros, hombres lobos y zombis a lo largo de la historia entre la realidad y la fantasía", en Revista U.D.C.A Actualidad y Divulgación Cientifica, vol. 19, núm. 2, Colombia: Universidad de Ciencias Aplicadas y Ambientales. Cantú, Rodrigo et al. (2012), "Impacto psicosocial en personas que viven con VIH-sida en Monterrey, México”, en Psicología y Salud, vol. 22, núm. 2, México: Instituto de Investigaciones Psicológicas de la Universidad Veracruzana.

Cardona, Jaiberth y Luis Higuita-Gutiérrez (2014), "Impacto del VIH/SIDA sobre la calidad de vida: metaanálisis 2002-2012”, en Revista Española de Salud Pública, vol. 88, núm. 1, España: Ministerio de Sanidad Servicios Sociales e Igualdad.

Cardona, Jaiberth (2010), "Representaciones sociales de calidad de vida relacionada con la salud en personas con VIH/SIDA, Medellín, Colombia”, en Revista de Salud Pública, vol. 12, núm. 5, Colombia: Instituto de Salud Pública, Facultad de Medicina, Universidad Nacional de Colombia.

Chong, Francisco et al. (2012), "Estrategias de personas con VIH para enfrentar el estigma asociado al VIH/sida: Pacientes del Hospital General de Huixtla, Chiapas”, en Estudios fronterizos, vol. 13, núm. 25, México: Universidad Autónoma de Baja California.

Díaz, Carmen et al. (2014), "Conocimientos sobre VIH/SIDA en adolescentes de una universidad en Cartagena-Colombia, 2011”, en Hacia la promoción de la salud, vol. 19, núm. 2, Colombia: Universidad de Caldas.

Domínguez, María y Domínguez, Deisy (2005), "Percepciones sociales de la juventud sobre el VIH/SIDA en Cuba”, en Revista Sexología y Sociedad, vol. 11, núm. 29, Cuba: Centro Nacional de Educación Sexual.

Gadamer, Hans-Georg (1998), El giro hermenéutico, España: Cátedra.

García, Alejandra et al. (2014), "Conocimientos y prácticas de riesgo ante el VIH/SIDA en adolescentes de la Facultad de Planeación Urbana y Regional de la Universidad Autónoma del Estado de México”, en Revista de Medicina e Investigación, vol. 2, núm. 2, México: Universidad Autónoma del Estado de México.

Gaviria, Gladys et al. (2015), "Prevalencia del VIH/SIDA y conductas de riesgo en internos de centro carcelario del distrito de Barranquilla”, en Revista Cientifica Salud Uninorte, vol. 31, núm. 1, Colombia: División de Ciencias de la Salud de la Universidad del Norte.

Ghiso, Alfredo y Ospina, Viviana (2010), "Naturalización de la intimidación entre escolares: un modo de construir lo social", en Revista Latinoamericana de Ciencias Sociales, Niñez y Juventud, vol. 8, núm. 1, Colombia: Universidad de Manizales.

Jacques, C. et al. (2015), "Explicaciones de las prácticas sexuales de riesgo en hombres que tienen sexo con hombres", en Gaceta Sanitaria, vol. 29, núm. 4, España: Sociedad Española de Salud Pública y Administración Sanitaria.

Katz, Ingrid et al. (2013), "Impact of HIV-related stigma on treatment adherence: systematic review and meta-synthesis", en Journal of the International AIDS Society, vol. 16, núm. 3, Suiza: International AIDS Society.

Lopera, Mónica María et al. (2011), "Acceso de las personas con VIH al sistema de salud colombiano y sus costos relacionados desde una perspectiva individual y familiar, Bogotá, 2010", en Gerencia y Politicas en Salud, vol. 10, núm. 20, Colombia: Pontificia Universidad Javeriana.

López, Julio et al. (2009), "The economic costs and health-related quality of life of people with HIV/AIDS in the Canary Islands, Spain”, en BMC Health Services Research, vol. 9, Reino Unido: Health Research \& Educational Trust. 
Convergencia Revista de Ciencias Sociales, núm. 76, 2018, Universidad Autónoma del Estado de México

Meléndez, Erick (2014), "VIH y pobreza: cambios socioeconómicos posteriores al diagnóstico”, Tesis doctoral, El Salvador: Universidad Dr. José Matías Delgado. Disponible en: http://redicces.org.sv/jspui/handle/10972/1884 [25 de noviembre de 2016].

Morales, M. et al. (2012), "La prevención social del VIH/SIDA. Un desafío pendiente", en Santiago, núm. 127, Cuba: Facultad de Ciencias Sociales, Universidad de Oriente.

Nhamba, Luis et al. (2014), "Depresión en personas con VIH en dos municipios de Angola", en Revista Cubana de Salud Pública, vol. 40, núm. 4, Cuba: Centro Nacional de Información de Ciencias Médicas.

ONUSIDA (2017) (Programa Conjunto de las Naciones Unidas sobre el VIH/Sida), Estadisticas mundiales sobre el VIH. Disponible en: http://www.unaids.org/es/resources/ fact-sheet [1 de octubre de 2017].

Orcasita, Linda et al. (2010), "Apoyo social y conductas de riesgo en adolescentes diagnosticados y no diagnosticados con VIH/SIDA en Cali-Colombia”, en Revista virtual Universidad Católica del Norte, núm. 31, Colombia. Disponible en: http://revistavirtual. ucn.edu.co/index.php/RevistaUCN/article/view/41/91 [25 de noviembre de 2016].

Passerino, Leila (2013), "Imaginarios, biomedicina y normatividad: una respuesta a los procesos de estigmatización y discriminación por VIH”, en Revista Ciencias de la Salud, vol. 11, núm. 2, Colombia: Universidad del Rosario.

Pfeiffer, María (2009), "Investigación en medicina y Derechos Humanos", en Andamios, vol. 6, núm. 12, México: Universidad Autónoma de la Ciudad de México.

Salcedo, Juan Pablo et al. (2013), "Aportes de la Organización Internacional del Trabajo al mundo laboral de las personas con VIH/SIDA”, en Revista Cubana de Salud Pública, vol. 39, núm. 4, Cuba: Centro Nacional de Información de Ciencias Médicas.

Sánchez, M. et al. (2016), "Estigmatización y usos léxicos en el tratamiento informativo del VIH/Sida en cinco diarios mexicanos de 2012 a 2013”, en Comunicación y Sociedad, núm. 25, México: Universidad de Guadalajara.

Sowell, Richanrd y Phillips, Kenneth (2010), "Understanding and responding to HIV/ AIDS stigma and disclosure: An international challenge for mental health nurses”, en Inssues in Mental Health Nursing, vol. 31, núm. 6, Reino Unido: Taylor \& Francis.

Tamayo, Byron et al. (2015), "Estigma social en la atención de personas con VIH/SIDA por estudiantes y profesionales de las áreas de la salud, Medellín, Colombia”, en Revista Ciencias de la Salud, vol. 13, núm. 1, Colombia: Universidad del Rosario.

Tavera, Mariela (2010), "Calidad de vida relacionada a la salud en pacientes con VIH", en Revista Peruana de Epidemiología, vol. 14, núm. 3, Perú: Sociedad Peruana de Epidemiología.

Teva, Inmaculada et al. (2012), “Situación epidemiológica actual del VIH/SIDA en Latinoamérica en la primera década del siglo XXI: Análisis de las diferencias entre países”, en Revista Médica de Chile, vol. 140, núm. 1, Chile: Sociedad Médica de Santiago.

Trinidad, Antonio et al. (2006), Teoria fundamentada" grounded theory": La construcción de la teoría a través del análisis interpretacional, España: Centro de Investigaciones Sociológicas.

Valdez, C. et al. (2015), "Reflexión de los determinantes sociales de la conducta sexual en hombres que tiene n relaciones sexuales con hombres", en Cuidados de Enfermería y Educación en Salud, vol. 2, núm. 1, Chile: Universidad de la Serena.

Valerio, Gabriel y Valenzuela, Jaime (2011), "Contactos de redes sociales en línea como repositorios de información”, en Revista de Universidad y Sociedad del Conocimiento, vol. 8, núm. 1, España: Cátedra de la UNESCO de e-learning de la UOC. 
Vargas, Jaime et al. (2009), "Estrategias de afrontamiento del sida en pacientes diagnosticados como seropositivos”, en Psicología y Salud, vol. 19, núm. 2, México: Instituto de Investigaciones Psicológicas de la Universidad Veracruzana.

Vermund, Sten (2014), "Global HIV epidemiology: A guide for strategies in prevention and care”, en Current HIV/AIDS Reports, vol. 11, núm. 2, Estados Unidos: Springer International Publishing.

Lemy Bran-Piedrahita. Coordinador General de Investigaciones en la Fundación Universitaria Católica del Norte, administrador en Servicios de Salud de la Universidad de Antioquia y especialista en Gerencia de la Fundación Universitaria CEIPA. Líneas de investigación: salud pública, salud mental, psicología social, ciencias sociales y conflicto armado. Publicaciones recientes: "Relación médico-paciente: impacto en las campañas de promoción y prevención para personas con VIH en Medellín”, en Revista de Salud Pública, vol. 18, núm. 4, Colombia: Universidad Nacional de Colombia (2016) e "Influencia del estigma en torno al VIH en el acceso a los servicios de salud", en Revista Salud Pública de México, vol. 57, núm. 3, México (2015).

Lucía Palacios-Moya. Docente Investigadora en la Institución Universitaria Escolme. Administradora en Servicios de Salud de la Universidad de Antioquia y Magíster en Salud Pública de la Universidad CES. Líneas de investigación: salud pública, salud mental y enfermedades infecciosas. Publicaciones recientes: "Relación médico-paciente: impacto en las campañas de promoción y prevención para personas con VIH en Medellín", en Revista de Salud Pública, vol. 18, núm. 4, Colombia: Universidad Nacional de Colombia (2016) e "Influencia del estigma en torno al VIH en el acceso a los servicios de salud", en Revista Salud Pública de México, vol. 57, núm. 3, México (2015).

Viviana Bermúdez-Román. Administradora en Servicios de Salud de la Universidad de Antioquia. Líneas de investigación: salud pública, salud mental y enfermedades infecciosas. Publicaciones recientes: "Relación médico-paciente: impacto en las campañas de promoción y prevención para personas con VIH en Medellín”, en Revista de Salud Pública, vol. 18, núm. 4, Colombia: Universidad Nacional de Colombia (2016) e "Influencia del estigma en torno al VIH en el acceso a los servicios de salud”, en Revista Salud Pública de México, vol. 57, núm. 3, México (2015).

Isabel Cristina Posada-Zapata. Psicóloga y Magíster en Salud Pública de la Universidad de Antioquia, estudiante del Doctorado en Ciencias Sociales, 
Niñez y Juventud de la Universidad de Manizales. Líneas de investigación: salud pública y salud mental. Publicaciones recientes: "Relación médicopaciente: impacto en las campañas de promoción y prevención para personas con VIH en Medellín”, en Revista de Salud Pública, vol. 18, núm. 4, Colombia: Universidad Nacional de Colombia (2016); "Influencia del estigma en torno al VIH en el acceso a los servicios de salud", en Revista Salud Pública de México, vol. 57, núm. 3, México (2015) y "Significados al consumo de alcohol en habitantes de una comunidad rural, Antioquia, Colombia, 20102011", en Revista Ciencias de la Salud, vol. 13, núm. 1, Argentina: Universidad del Rosario (2015).

Recepción: 29 de marzo de 2017.

Aprobación: 30 de octubre de 2017. 